\title{
Screening for dysglycaemia using anthropometric indices in an adult population in Oman
}

Shyam Sundar Ganguly, ${ }^{1}$ Kamalesh Sarkar, ${ }^{2}$ Samir Al-Adawi ${ }^{3}$ and Abdul Aziz Al-Mahrezi ${ }^{1}$

${ }^{1}$ Department of Family Medicine and Public Health; ${ }^{3}$ Department of Behavioural Medicine, College of Medicine \& Health Sciences, Sultan Qaboos University, Muscat, Oman (Correspondence to: Shyam Ganguly: ganguly@squ.edu.om). ${ }^{2}$ Division of Epidemiology, National Institute of Cholera and Enteric Diseases, Kolkata, India.

\begin{abstract}
Background: A previous community-based cross-sectional survey conducted in a semi-urban community revealed that $44 \%$ of people aged $18+$ years manifest dysglycaemia, which appears to echo the national trend. There is lack of studies examining the role of anthropometric indices in people with dysglycaemia.
\end{abstract}

Aim: We explored the screening ability of anthropometric indices, body mass index (BMI), waist circumference (WC), waist-to-hip ratio (WHR), and waist-to-height ratio (WHtR) to detect dysglycaemia in the adult Omani population based on a community-based survey conducted in 2005. The potential of anthropometric indices to detect the presence of glycaemic disorder could aid in detection, prevention and health education.

Methods: A total of 480 male and 795 female subjects aged $18+$ years were included in this study. The prevalence of dysglycaemia was analysed using the American Diabetic Association criteria. Logistic regression approach and ReceiverOperating Characteristic (ROC) curve analysis was performed.

Results: The analysis revealed that mean values of age, BMI, WC, WHR and WHtR increased significantly from normoglycemic to pre-diabetic and further to diabetic in both sexes $(P<0.0001)$. Dysglycemia showed an increasing prevalence with age. WHtR showed the highest sensitivity for detecting dysglycemia in all age groups compared to other anthropometric indices with sensitivity rate of $94.4 \%$ in $\geq 45$ years, $88.6 \%$ in (25-44) years and $45.6 \%$ in age group <25 years.

Conclusion: Among the anthropometric indices we investigated, WHtR was the best predictor of dysglycaemia among Omani adults aged $>25$ years.

Key words: Anthropometric measurements, Dysglycemia, Diabetes, ROC Curve

Citation: Ganguly SS; Sarkar K; Al-Adawi S; Al-Mahrezi A. Screening for disglycaemia using anthropometric indices in an adult population in Oman. East Mediterr Health J. 2018;24(3):254-261. https://doi.org/10.26719/2018.24.3.254

Received: 08/11/16; accepted: 05/03/17

Copyright @ World Health Organization (WHO) 2018. Some rights reserved. This work is available under the CC BY-NC-SA 3.0 IGO license https:// creativecommons.org/licenses/by-nc-sa/3.o/igo

\section{Introduction}

Oman has been internationally praised for the fulfilment of most of the Millennium Development Goals 2015 (1), however, along with the challenge of communicable diseases, there is an increasing challenge from noncommunicable diseases, and diabetes appears to be prominent, precipitated by rapid urbanisation and rising standards of living $(2,3)$. According to 2000 data from the Ministry of Health, the prevalence of diabetes was $11.6 \%$, rising to $12.3 \%$ in $2010(4,5)$. Approximately $29 \%$ of the Omani population was classed as overweight and $9 \%$ as obese (6). In a population-based national survey $22 \%$ of those surveyed were overweight or obese (7). Obesity and overweight are recognised as independent risk factors for the development of diabetes and dysglycaemia $(8,9)$. In a 2010 community-based cross-sectional study, 35\% of the Omani men were prediabetic; advanced age and being overweight were identified as strong contributing factors (10).

Within the emerging epidemic of dysglycaemia, more studies are needed to identify anthropometric characteristic that would have a direct bearing on dysglycaemia. In the available literature, various phenotypical indicators have been linked to the presence of dysglycaemia. In Western population, body mass index (BMI) has been associated with the presence of dysglycaemia (11). The World Health Organization has provided guidelines for using BMI to assess dysglycaemia with a cut off value of $25 \mathrm{~kg} / \mathrm{m}^{2}$ (12). It is not clear whether this is applicable to the Omani population. Waist circumference (WC) and waist-to-hip ratio (WHR) have also been suggested as indicators of intra-abdominal fat. Some studies have suggested that WC and WHR are better predictors of dysglycaemia than BMI (13-15). There is also a dissenting view suggesting the relationship between WHR and dysglycaemia is poor. Some preliminary data suggest that WHR correlates more weakly with glucose tolerance; sex is also a significant confounding factor (16). A few studies have reported that waist-to-height-ratio (WHtR) is a better screening tool than other anthropometric indices, with a cut off value of $0.5(17,18)$. Against such a conflicting background, more studies are needed to determine the correlation between anthropometric measures and dysglycaemia. This would help to detect dysglycaemia cases early among apparently 
healthy people, and, in turn, mitigate morbidity and mortality. This study aims to explore the screening capacity of anthropometric indices to adequately detect dysglycaemia in adult Omani population.

\section{Methods}

\section{Survey}

In this study, we used the data from a cross-sectional, community-based survey carried out on 1275 Omani adults, aged $\geq 18$ years, residing in a semi-urban satellite town of Bidbid, which is situated $30 \mathrm{~km}$ west of the capital, Muscat, during September 2004 to February 2005.

The following exclusion criteria were used: participants with diabetics who were taking medication or insulin for the disease; pregnant women or mothers within 3 months postpartum; and people with conditions that were likely to interfere with research procedures, e.g. inability to communicate with staff or having a persistent and intransigent illnesses.

\section{Sample design and participants}

A sample size of 1500 subjects was determined based on the estimated prevalence of prediabetes $(36 \%)(10)$ and diabetes $(12.3 \%)$ (4), a nonresponse rate of $10 \%$, an error margin of $5 \%$ with $95 \%$ confidence interval. We adopted a 2-stage random cluster sampling design. The first stage was the random selection of census enumeration areas, where each area comprised 100 households as defined by the Ministry of National Economy. Out of 100 census enumeration areas, 20 were randomly selected using a random number allocation method. A sampling frame of 6150 subjects was developed by conducting a census among the 20 randomly selected areas. The name, family name, sex, age, household and locality of all eligible subjects was recorded on field maps. In the second stage, 1500 subjects were randomly selected from the sampling frame using computer generated random numbers. All persons aged $\geq 18$ years in the selected households were invited to participate in the study. Of these, 1275 completed the structured pre-tested questionnaire, an overall response rate of $85 \%$.

\section{Anthropometric and laboratory measurements}

Blood glucose (both fasting and post-prandial, 2 hours following ingestion of $75 \mathrm{~g}$ glucose) was collected from the venous blood at sodium fluoride potassium oxalate tubes and tested at the laboratory after separating plasma on the same day, using Hitachi 911 automated clinical chemistry analysers (Boehringer-Mannheim). The reagents used were supplied by the same manufacturer. Glycaemic status according to the American Diabetes Association (ADA) criteria was used: $<5.6 \mathrm{mmol} / \mathrm{L}$ fasting normal, 5.6-6.9 mmol/L impaired fasting glucose and $\geq 7.0 \mathrm{mmol} / \mathrm{L}$ diabetes mellitus (19,20). Dysglycaemia was defined as a subject having fasting plasma glucose $\geq 5.6$ $\mathrm{mmol} / \mathrm{L}(100 \mathrm{mg} / \mathrm{dL})$ and/or impaired glucose tolerance of $\geq 7.8 \mathrm{mmol} / \mathrm{L}(140 \mathrm{mg} / \mathrm{dL})$ including prediabetes and diabetes. The fasting plasma glucose and oral glucose tolerance levels were estimated from venous blood at the laboratory of Sultan Qaboos University Hospital according to the standard protocol. Height and weight were measured using a stature meter and high precision digital weighing machine with regular accuracy checks. Weight/height was taken in a standing posture, wearing light clothing and without shoes. The BMI was calculated as weight $/ \mathrm{height}^{2}\left(\mathrm{~kg} / \mathrm{m}^{2}\right)$ and individuals with $\mathrm{BMI} \geq 25$ $\mathrm{kg} / \mathrm{m}^{2}$ were considered overweight. Waist circumference was measured using a steel measuring tape with measurements made half way between the lower border of the ribs and the iliac crest in a horizontal plane. A value of $\geq 94.0 \mathrm{~cm}$ for males and $\geq 80.0 \mathrm{~cm}$ for females (the cut-off values recommended for Eastern Mediterranean and Middle Eastern Arab populations) was considered overweight (abnormal) (21). Similarly, hip circumference was measured at the widest point over the buttocks and the waist-to-hip ratio (WHR) was calculated; WHR $\geq 0.95$ $\mathrm{cm}$ for males and $\geq 0.85 \mathrm{~cm}$ for females was considered abnormal $(22,23)$. Waist-to-height ratio (WHtR) was also calculated for each individual and if the ratio was $\geq 0.5$, then the individual was considered as having abnormal central obesity (24).

Dysglycaemia or glycaemic disorder is an agedependent phenomenon and magnitude of problem usually remains low in young adult, medium in middle aged and high in older age group as observed in several studies $(25,26)$. On the other hand, sensitivity of a screening test is influenced by the prevalence of disease under investigation in a community (27). Considering the above, age-related prevalence of dysglycaemia was analysed. Following this, sensitivity analysis of dysglycaemia using various anthropometric indices (BMI, WC, WHR and WHtR) was done for each age group to obtain the sensitivity status. This was also done to understand whether the anthropometric tool could be uniformly applicable to all age groups so far as sensitivity was concerned. If not, a possible cut-off value was expected to be explored based on sensitivity status. Finally, the receiver operating characteristic curve was developed for the indices based on the findings of age group sensitivity to obtain the test accuracy in subjects with values below and above the cut-off (28). Receiver operating characteristic curves were used to determine the predictive power of various anthropometric indices for glycaemic status by comparing areas under the curve.

The Medical Research and Ethics Committee of the College of Medicine and Health Sciences, Sultan Qaboos University, approved the study. All participants gave their written informed consents prior to participating in the study.

\section{Statistical analysis}

Descriptive analysis for continuous variables was used to calculate mean values and standard deviation. Prevalence and frequencies were expressed as percentages. The differences in means of the anthropometric indices and age between the 3 glycaemic categories were assessed using 1-way analysis of variance (ANOVA). Where there was a lack of homogeneity of variance, the Kruskal-Wallis 
test was used to compare the distributions between the 3 glycaemic categories. When ANOVA provided evidence of significant difference between the groups, a post-hoc test, Dunnett's T3 test was used for pair-wise comparison of the means.

To establish the relationship between anthropometric indices of obesity and glycaemic status, odds ratios and their 95\% confidence intervals were estimated using logistic regression models, after adjusting for age (29). The chi-squared trend test was used for trend analysis for percentages of sensitivity and specificity across the age groups. $P$-value ( 2 -tailed) $<0.05$ was considered statistically significant. All data were analysed using SPSS, version 23 .

\section{Results}

A total of 480 males and 795 females aged $\geq 18$ years consented to participate in this study. Table 1 shows mean values for various anthropometric indices according to glycaemic status. The mean age for both normoglycaemic males and females was similar, around 29 years, but mean age of females was slightly older for both types of dysglycaemia, impaired fasting glucose and diabetes mellitus. An average male appears to have had a gap of 5 years prior to development of diabetes from the prediabetic status, while females took about 7 years to reach full-blown symptoms. A similar observation was noted for developing impaired fasting glucose from normoglycaemic status: for males the average gap was 4 years but for females it was about 7 years. This indicates that diabetes progresses more slowly and at an older age in females. These differences were statistically significant $(P<0.05)$. Mean values of BMI, WC, WHR and WHtR differed significantly from normoglycaemic to impaired fasting glucose and further to diabetes in both sexes (Table 1).

Overall prevalence of dysglycaemia was $44.1 \%$ (combining all ages and both sexes) (Table 2). It is evident that the prevalence of dysglycaemia increased in both sexes with age. Prevalence in males was $49.4 \%$ and in females 40.9\%; prevalence was slightly lower in females in each age group compared to their male counterparts except for the $\geq 45$ years group. This indicates that diabetes is an age-dependent condition for both sexes.

It is evident that older age, BMI $\geq 25 \mathrm{~kg} / \mathrm{m}^{2}$, WC $\geq 94.0$ (male) $/ \geq 80.0$ (female), WHR $\geq 0.95$ (male) $/ \geq 0.85$

Table 1. Anthropometric indices in relation to glycaemic status for male and female adults in Oman, 2004-2005

\begin{tabular}{|c|c|c|c|c|c|c|}
\hline \multirow[t]{3}{*}{ Index } & \multicolumn{2}{|c|}{ Normoglycaemic } & \multicolumn{4}{|c|}{ Dysglycaemic } \\
\hline & \multirow[t]{2}{*}{ Mean (SD) } & \multirow[t]{2}{*}{$95 \%$ CI } & \multicolumn{2}{|c|}{ IFG } & \multicolumn{2}{|c|}{ DM } \\
\hline & & & Mean (SD) & $95 \%$ CI & Mean (SD) & $95 \% \mathrm{CI}$ \\
\hline Males (No.) & 258 & - & 195 & - & 27 & - \\
\hline Age (years) & $29.20(10.94)$ & $27.86-30.55$ & $33.84(12.99)^{\mathrm{a}}$ & $32.00-35.67$ & $38.63(11.25)^{b}$ & $34.18-43.08$ \\
\hline BMI $\left(\mathrm{kg} / \mathrm{m}^{2}\right)$ & $24.67(4.50)$ & $24.12-25.23$ & $26.22(4.74)^{\mathrm{a}}$ & $25.55-26.88$ & $28.77(4.85)^{b}$ & $26.76-30.77$ \\
\hline $\mathrm{WC}(\mathrm{cm})$ & 85.33 (11.39) & $83.92-86.73$ & $90.14(11.42)^{\mathrm{a}}$ & $88.54-91.75$ & $94.88(10.95)^{\mathrm{b}}$ & $90.46-99.31$ \\
\hline WHR & $0.88(0.06)$ & $0.87-0.89$ & $0.91(0.07)^{\mathrm{a}}$ & $0.89-0.92$ & $0.94(0.05)^{b, c}$ & $0.92-0.96$ \\
\hline WHtR & $0.51(0.07)$ & $0.50-0.52$ & $0.54(0.07)^{\mathrm{a}}$ & $0.53-0.55$ & $0.58(0.06)^{b, c}$ & $0.55-0.60$ \\
\hline Females (No.) & 504 & - & 258 & - & 33 & - \\
\hline Age (years) & 29.17 (9.69) & $28.32-30.02$ & $36.26(11.84)^{\mathrm{a}}$ & $34.79-37.73$ & $43.81(13.01)^{b, c}$ & $39.12-48.50$ \\
\hline BMI $\left(\mathrm{kg} / \mathrm{m}^{2}\right)$ & $24.65(5.20)$ & $24.19-25.10$ & $27.99(6.16)^{\mathrm{a}}$ & $27.23-28.74$ & $29.98(6.41)^{b}$ & $27.70-32.25$ \\
\hline $\mathrm{WC}(\mathrm{cm})$ & $78.80(12.67)$ & $77.70-79.91$ & $88.58(13.99)^{\mathrm{a}}$ & $86.86-90.29$ & $97.24(13.89)^{b, c}$ & $92.32-102.17$ \\
\hline WHR & $0.82(0.09)$ & $0.81-0.82$ & $0.88(0.09)^{\mathrm{a}}$ & $0.87-0.89$ & $0.96(0.08)^{b, c}$ & $0.93-0.99$ \\
\hline WHtR & $0.51(0.08)$ & $0.05-0.52$ & $0.58(0.09)^{\mathrm{a}}$ & $0.57-0.59$ & $0.64(0.09)^{b, c}$ & $0.61-0.67$ \\
\hline
\end{tabular}

P-value (ANOVA) <0.001 for all.

$C I=$ confidence interval; IFG = impaired fasting glucose; $D M=$ diabetes mellitus; $S D=$ standard deviation; $B M I=$ body mass index; WC = waist circumference; WHR = waist-to-hip-ratio; WHtR $=$ waist-to-height-ratio.

${ }^{a} P<0.01$ for normoglycaemic versus IFG.

${ }^{b} \mathrm{P}<0.01$ for normoglycaemic versus $\mathrm{DM}$.

${ }^{c} P<0.05$ for IFG versus DM.

\begin{tabular}{|c|c|c|c|c|c|c|}
\hline Age (years) & $\begin{array}{l}\text { No. of males } \\
\text { screened }\end{array}$ & $\begin{array}{c}\text { Dysglycaemia } \\
\text { No. (\%) }\end{array}$ & $\begin{array}{l}\text { No. of females } \\
\text { screened }\end{array}$ & $\begin{array}{c}\text { Dysglycaemia } \\
\text { No. (\%) }\end{array}$ & Total screened & $\begin{array}{c}\text { Dysglycaemia } \\
\text { No. (\%) }\end{array}$ \\
\hline$<25$ & 164 & $58(35.4)$ & 245 & $59(24.1)$ & 409 & $117(28.6)$ \\
\hline $25-44.9$ & 250 & $135(54)$ & 461 & $202(43.8)$ & 711 & $337(47.4)$ \\
\hline$\geq 45$ & 66 & $44(66.7)$ & 89 & $64(71.9)$ & 155 & $108(69.7)$ \\
\hline Total & 480 & $237(49.4)$ & 795 & 325 (40.9) & 1275 & $562(44.1)$ \\
\hline
\end{tabular}


(female) and WHtR $\geq 0.5$ are significantly associated with dysglycaemia $(P<0.001)$ (Table 3). For all 4 anthropometric indices, females were at comparatively greater risk of developing dysglycaemia compared with males.

The sensitivity and specificity for detecting dysglycaemia using each anthropometric measurement were calculated separately for each age group. Individually WHtR showed the highest sensitivity for detecting dysglycaemia for all age groups: $94.4 \%$ in the oldest age group ( $\geq 45$ years), $88.6 \%$ in the middle age group (25.0-44.9 years) and $45.6 \%$ in the youngest age group (<25 years) (Table 4$)$. None of the measures

\begin{tabular}{|c|c|c|c|c|c|c|}
\hline \multirow[t]{2}{*}{ Index } & \multicolumn{3}{|c|}{ Males } & \multicolumn{3}{|c|}{ Females } \\
\hline & OR & $95 \% \mathrm{CI}$ & $P$-value & OR & $95 \% \mathrm{CI}$ & P-value \\
\hline \multicolumn{7}{|l|}{ Age (years) } \\
\hline$<25$ & 1 & & & 1 & & \\
\hline $25-44$ & 2.14 & $1.43-3.21$ & $<0.0001$ & 2.26 & $1.74-3.47$ & $<0.0001$ \\
\hline$\geq 45$ & 3.66 & $2.00-6.68$ & $<0.0001$ & 8.07 & $4.67-13.94$ & $<0.0001$ \\
\hline \multicolumn{7}{|l|}{ BMI (kg/m2) } \\
\hline$<25.0$ & 1 & & & 1 & & \\
\hline$\geq 25.0$ & 2.11 & $1.43-3.10$ & $<0.0001$ & 2.60 & $1.90-3.55$ & $<0.0001$ \\
\hline \multicolumn{7}{|l|}{ WC (cm) } \\
\hline$<94.0(\mathrm{M}) /<80.0(\mathrm{~F})$ & 1 & & & 1 & & \\
\hline$\geq 94.0(\mathrm{M}) / \geq 80.0(\mathrm{~F})$ & 2.12 & $1.40-3.23$ & $<0.0001$ & 3.11 & $2.22-4.37$ & $<0.0001$ \\
\hline \multicolumn{7}{|l|}{ WHR } \\
\hline$<0.95(\mathrm{M}) /<0.85(\mathrm{~F})$ & 1 & & & 1 & & \\
\hline$\geq 0.95(\mathrm{M}) / \geq 0.85(\mathrm{~F})$ & 1.90 & $1.19-3.02$ & 0.007 & 3.78 & $2.68-5.33$ & $<0.0001$ \\
\hline \multicolumn{7}{|l|}{$W_{t} R$} \\
\hline$<0.5$ & 1 & & & 1 & & \\
\hline$\geq 0.5$ & 2.43 & $1.54-3.81$ & $<0.0001$ & 2.98 & $2.05-4.33$ & $<0.0001$ \\
\hline
\end{tabular}

$M=$ male $F=$ female $; B M I=$ body mass index WC = waist circumference WHR = waist-to-hip ratio; $W H t R=$ waist-to-height ratio.

Table 4. Sensitivity and specificity of selected anthropometric indices for detecting dysglycaemia in three age groups in Omani adults

\begin{tabular}{|c|c|c|c|c|c|c|}
\hline \multirow[t]{3}{*}{ Index (cut-off) } & \multirow{2}{*}{\multicolumn{2}{|c|}{$\begin{array}{c}\text { Age }<25 \text { years } \\
\quad(n=409)\end{array}$}} & \multirow{2}{*}{\multicolumn{2}{|c|}{$\begin{array}{c}\text { Age 25-44 years } \\
(n=711) \\
\text { Sensitivity }\end{array}$}} & \multirow{2}{*}{\multicolumn{2}{|c|}{$\begin{array}{c}\text { Age } \geq 45 \text { years } \\
\quad(n=155)\end{array}$}} \\
\hline & & & & & & \\
\hline & TP/ TP+FN & Sensitivity \% & TP/ TP+FN & Sensitivity \% & TP/ TP+FN & Sensitivity $\%$ \\
\hline BMI ( $\geq 25.0)$ & $44 / 117$ & 37.6 & $249 / 335$ & 74.3 & $64 / 108$ & 59.3 \\
\hline $\begin{array}{l}W C(\mathrm{~cm}) \\
(M \geq 94 / F \geq 80)\end{array}$ & $30 / 117$ & 25.6 & $234 / 335$ & 69.8 & $75 / 108$ & 69.4 \\
\hline $\begin{array}{l}\text { WHR } \\
(\mathrm{M} \geq 0.95 / \mathrm{F} \geq 0.85)\end{array}$ & $18 / 117$ & 15.4 & $194 / 335$ & 57.9 & $86 / 108$ & 79.6 \\
\hline WHtR ( $\geq 0.5)$ & $52 / 114$ & 45.6 & $288 / 325$ & 88.6 & $101 / 107$ & 94.4 \\
\hline \multirow[t]{3}{*}{$\begin{array}{l}\operatorname{BMI}(\geq 25.0) \text { and/or } \\
\operatorname{WHtR}(\geq 0.5)\end{array}$} & $54 / 114$ & 47.5 & $291 / 324$ & 89.8 & $101 / 107$ & 94.4 \\
\hline & \multicolumn{6}{|c|}{ Specificity } \\
\hline & $\mathrm{TN} / \mathrm{TN}+\mathrm{FP}^{*}$ & Specificity & TN/ TN+FP & Specificity & $\mathrm{TN} / \mathrm{TN}+\mathrm{FP}^{*}$ & Specificity \\
\hline BMI ( $\geq 25.0)$ & $207 / 289$ & 71.6 & $189 / 373$ & 50.6 & $30 / 47$ & 63.8 \\
\hline $\begin{array}{l}W C(\mathrm{~cm}) \\
(M \geq 94 / F \geq 80)\end{array}$ & $230 / 289$ & 79.6 & $194 / 373$ & 52.0 & $27 / 47$ & 57.4 \\
\hline $\begin{array}{l}\text { WHR } \\
(\mathrm{M} \geq 0.95 / \mathrm{F} \geq 0.85)\end{array}$ & $261 / 289$ & 90.3 & $239 / 373$ & 64.1 & $23 / 47$ & 48.9 \\
\hline WHtR $(\geq 0.5)$ & $196 / 284$ & 69.0 & $110 / 355$ & 30.9 & $10 / 45$ & 22.2 \\
\hline $\begin{array}{l}\operatorname{BMI}(\geq 25.0) \text { and/or } \\
\operatorname{WHtR}(\geq 0.5)\end{array}$ & $185 / 284$ & 65.1 & $104 / 355$ & 29.3 & $10 / 45$ & 22.2 \\
\hline
\end{tabular}

P-value $<0.001$ for all.

$\mathrm{TP}=$ true positive; $\mathrm{FN}=$ false negative; $M=$ male $F=$ female; $B M I=$ body mass index $; \mathrm{WC}=$ waist circumference; $\mathrm{WHR}=$ waist-to-hip ratio; $\mathrm{WH} t \mathrm{R}=$ waist-to-height ratio; $\mathrm{TN}=$ true negative; $F P=$ false positive. 
showed sensitivity $\geq 50 \%$ for detecting dysglycaemia in the age group $<25$ years. Combining 2 sequential tests with BMI and WHtR to obtain a net gain in sensitivity in the youngest age group, sensitivity increased to $47.5 \%$, $1.9 \%$ above WHtR alone.

Our analysis indicates that if dysglycaemia is screened for using WHtR, it would have a detecting ability of around $90 \%$ among those aged $\geq 25$ years, but less than $50 \%$ among those aged $<25$ years. Specificity in the youngest age group was highest with WHR $(90 \%)$, followed by WC (79.6\%) and BMI (71.6\%). Specificity was lower for all indices in the older age groups (Table 4).

The areas under the receiver operating characteristic curves for the 4 anthropometric indices at their respective cut-off values, i.e. are most likely to identify dysglycaemia, are shown in Table 5 . The receiver operating characteristic area in those aged $<25$ years are: BMI 0.551; WC 0.605; WHR 0.640; WHtR 0.598 (Table 5). The area under the ROC curve for each of the 4 anthropometric indices is greater for the age group $\geq 25$ years compared with < 25 years, indicating that the predictive power of each of the 4 anthropometric indices to detect dysglycaemia is greater for the older age group.

\section{Discussion}

Since noncommunicable diseases are on rise in almost all countries in the region, including Oman, initiatives were taken to identify some suitable anthropometric marker/s that would help in identifying the susceptible population at risk of developing dysglycaemia. Several studies have been conducted to explore the possible role of anthropometric marker/s for dysglycaemia. Some indicated WHtR as a strong predictor compared to WC, WHR and BMI $(9,24,30,31)$.

As in other studies $(25,26)$, we found the prevalence of dysglycaemia to be significantly associated with the older age in both sexes. We attempted to highlight the screening ability of 4 anthropometric indices, BMI, WC, WHR and WHtR, in detecting dysglycaemia among 3 age groups. The study showed an association between anthropometric measurements (BMI, WC, WHR, WHtR) with their cut off values and dysglycaemia. Similar

\begin{tabular}{|c|c|c|c|c|}
\hline \multicolumn{5}{|c|}{$\begin{array}{l}\text { Table 5. Area under the receiver operating characteristic } \\
\text { curves illustrating the power of the anthropometric indices in } \\
\text { predicting dysglycaemia for Omani adults in two age groups }\end{array}$} \\
\hline \multirow[t]{3}{*}{ Index } & \multicolumn{4}{|c|}{ Age (years) } \\
\hline & \multicolumn{2}{|c|}{$<25(n=409)$} & \multicolumn{2}{|c|}{$\geq 25(n=866)$} \\
\hline & $\begin{array}{l}\text { Area under } \\
\text { the curve }\end{array}$ & $95 \%$ CI & $\begin{array}{l}\text { Area under } \\
\text { the curve }\end{array}$ & $95 \% \mathrm{CI}$ \\
\hline BMI & 0.551 & $0.488-0.613$ & $0.655^{*}$ & $0.618-0.691$ \\
\hline WC & $0.605^{*}$ & $0.544-0.666$ & $0.685^{*}$ & $0.650-0.720$ \\
\hline WHR & $0.640^{*}$ & $0.580-0.701$ & $0.694^{*}$ & $0.659-0.729$ \\
\hline WHtR & $0.598^{*}$ & $0.537-0.659$ & $0.686^{*}$ & $0.651-0.721$ \\
\hline
\end{tabular}

${ }^{*} \mathrm{P}<0.01$.

$\mathrm{CI}=$ confidence interval; $\mathrm{BMI}=$ body mass index; $\mathrm{WC}=$ waist circumference; $\mathrm{WHR}=$ waist-to-hip ratio; $\mathrm{WH} \mathrm{H} R=$ waist-to-height ratio. observations have been reported in other studies $(32,33)$.

It was observed that WHtR had the highest sensitivity in all 3 age groups; BMI showed the second highest sensitivity in the youngest age group and the lowest sensitivity rate in the oldest age group as observed in a similar study (34). In a study among Jordanian adult population, the comparison between the 4 anthropometric indices was carried out for detecting metabolic abnormalities (35). The study revealed that the WHtR had a strong association and performed better for the detection of high fasting blood glucose. The estimated values of areas under the curve and odds ratios corresponding to $\mathrm{WHtR}$ were very close to the estimated values in our study.

Sensitivity was $90 \%$ for WHtR in this study population, when the 2 older age groups were combined (i.e. age $\geq 25$ years.). This means WHtR would detect $90 \%$ of the dysglycaemia cases with a cut-off value of $\geq 0.5$, if used for community-based screening programmes for dysglycaemia (the cut off value for WHtR is the same for all age groups). This means WHtR may be used as a screening tool for dysglycaemia in communitybased screening among people aged $\geq 25$ years. Other advantages of this tool are: this test is cheap and easy to perform by health care workers once they are trained. Disadvantage include: lowering of sensitivity to $<50 \%$ when applied to the subjects aged $<25$ years. This agerelated change in sensitivity may be primarily due to the effect of increasing accumulation of visceral or intraabdominal fat with older age. In an individual, height remains fixed but ratio between waist circumference and height changes. On the other hand, WC and WHR did not show a comparable sensitivity to WHtR. Thus, in our study WHtR appears to be a better anthropometric predictor, which could be used for community-based screening of dysglycaemia.

As indicated by the analysis of data, younger age group ( $<25$ years) needs special attention as no anthropometric indicator showed a sensitivity $\geq 50 \%$. In principle, if 2 sequential screening tests are applied simultaneously, there is usually a net gain of sensitivity (36). Considering this principle, and since BMI showed the second highest sensitivity in the youngest age group, BMI was combined with WHtR, resulting in a slight increase in sensitivity. This indicates that even if both tests are combined, this would not be able to detect even $50 \%$ of the individuals in that age group with dysglycaemia. Consequently, finding a suitable screening tool for younger population poses a public health challenge and efforts must be continued to find a suitable predictor. 


\section{Acknowledgements}

The authors would like to thank the participants as well as other research workers who contributed to the outcomes of this study.

Funding: This study is a part of the AMAL Research Project supported by His Majesty Sultan Qaboos Strategic Research Trust Fund (Grant SR/MED/FAMCO/03/01) from Sultan Qaboos University.

Competing interests: None declared.

\section{Dépistage de la dysglycémie au moyen d'indices anthropométriques dans une population d'adultes à Oman}

\section{Résumé}

Contexte : Une enquête transversale communautaire précédemment réalisée dans une communauté semi-urbaine a révélé que $44 \%$ des personnes de plus de 18 ans présentaient une dysglycémie, ce qui semble correspondre à la tendance nationale. Il n'existe pas d'études permettant d'examiner le rôle des indices anthropométriques chez les sujets atteints de dysglycémie.

Objectif : Nous avons exploréla capacité diagnostique des indices anthropométriques, del'indice de masse corporelle (IMC), du tour de taille, du rapport tour de taille/tour de hanches, et du rapport tour de taille/taille pour détecter la dysglycémie dans la population d'adultes à Oman sur la base d'une enquête communautaire réalisée en 2005. Le potentiel des indices anthropométriques afin de détecter la présence de troubles de la glycémie pourrait contribuer au dépistage, à la prévention et l'éducation sanitaire.

Méthodes : Au total, 480 sujets masculins et 795 sujets féminins de plus de 18 ans ont été inclus dans cette étude. La prévalence de la dysglycémie a été analysée à l'aide des critères de l'Association américaine du diabète. On a recouru à l'approche de régression logistique et à l'analyse de la courbe ROC (caractéristique du fonctionnement du récepteur).

Conclusion : Parmi les indices anthropométriques que nous avons étudiés, le rapport tour de taille/taille était le meilleur prédicteur de la dysglycémie parmi les Omanais adultes âgés de plus de 25 ans.

$$
\begin{aligned}
& \text { فحص خلل سكر الدم لدى السكان البالغين في عُمان باستخدام مؤشر ات أنثروبومترية } \\
& \text { شيام جانجولي، كاماليش ساركار، سمير العدوي، عبد العزيز المحرزي }
\end{aligned}
$$

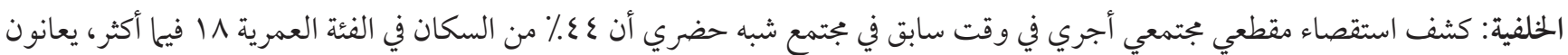

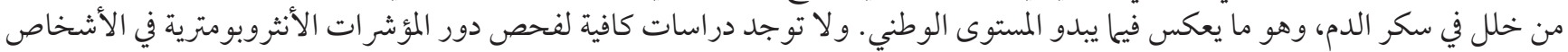

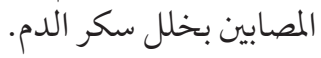

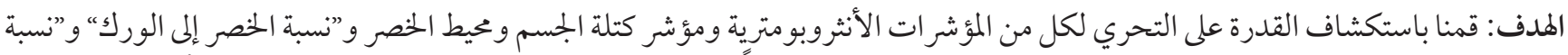

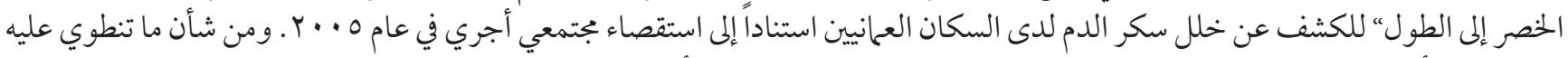

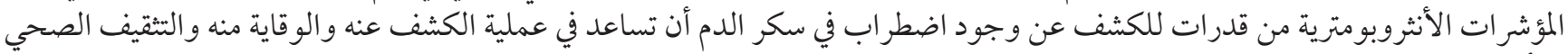

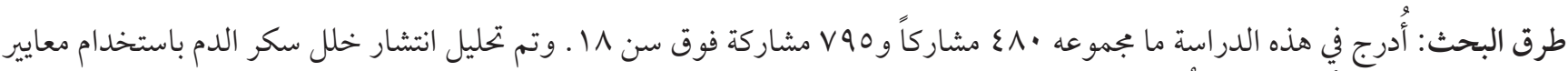

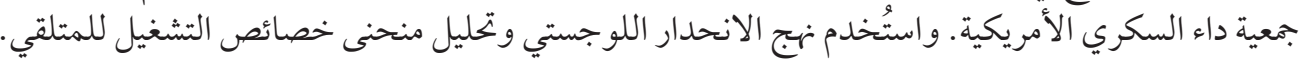

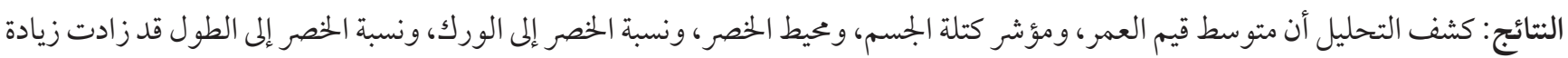

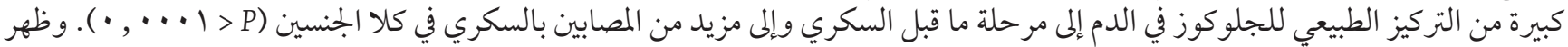

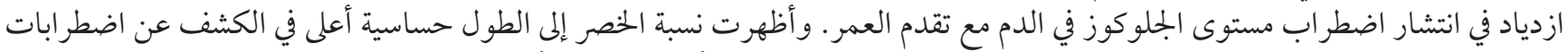

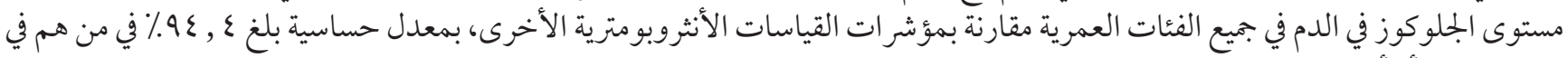

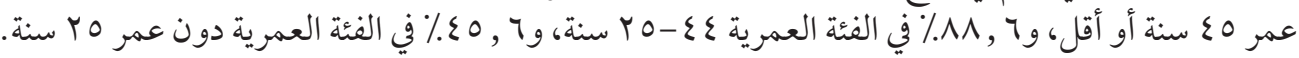

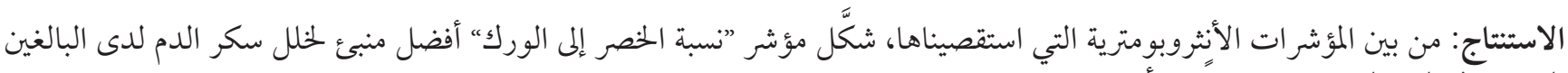
العمانيين في الفئة العمرية بن المر عاماً وما أكثر. 


\section{References}

1. Al-Lamki L. UN Millennium Development Goals and Oman: kudoks to Oman on its 4oth National Day. Sultan Qaboos Univ Med J. 2010 Dec;10(3):301-5.

2. Al-Riyami A, Abdelaty MA, Jaju S, Morsi M, Al- Kharusi H, Al-Shekaili W. World Health Survey 2008. Muscat, Oman: Ministry of Health; 2012.

3. Al_Lawati JA, Panduranga P, Al-Shaikh HA, Morsi M, Nohsin N, Khandekar RB, et al. Epidemiology of diabetes mellitus in Oman - results from two decades of research. Sultan Qaboos Univ Med J. 2015,15(2):210-7.

4. Al-Riyami et al., eds. National health survey 2000, vol. 1. Study of life style risk factors. Muscat: Ministry of Health, UNICEF and UNFPA; 2000.

5. Al Riyami A, Elaty MA, Morsi M, Al Kharusi H, Al Shukaily W, Jaju S. Oman world health survey: part 1 - methodology, sociodemographic profile and epidemiology of non-communicable diseases in Oman. Oman Med J. 2012 Sep;27(5):425-43.

6. El-Aty MA, Mabry R, Morsi M, Al-Lawati J, Al-Riyami A, El-Sayed M. Metabolic syndrome and its components: secondary analysis of the World Health Survey, Oman. Sultan Qaboos Univ Med J. 2014 Nov;14(4):e460-7. Epub 2014 Oct 14.

7. Rahim HF, Sibai A, Khader Y, Hwalla N, Fadhil I, Alsiyabi H, et al. Non-communicable diseases in the Arab world. Lancet. 2014 Jan;383(9914):356-67. PMID:24452044

8. Kelly T, Yang W, Chen CS, Reynolds K, He J. Global burden of obesity in 2005 and projections to 2030. Int J Obesity. 2008;32:14317. PMID:18607383

9. Bener Al, Yousafzai MT, Darwish S, Al-Hamaq AO, Nasralla EA, Abdul-Ghani M. Obesity index that better predict metabolic syndrome: body mass index, waist circumference, waist hip ratio, or waist height ratio. J Obes. 2013;269038. doi: $10.1155 / 2013 / 269038$.

10. Al-Shafee MA, Bhargava K, Al-Farsi Y, Mcilvenny S, Al-Mandhari A, Al-Adawi S, et al. Prevalence of pre-diabetes and associated risk factors in an adult Omani population. Int J Diabetes Dev Ctries. 2011;31(3):166-73.

11. Kahn HS, Bullard KM. Beyond body mass index: advantages of abdominal measurements for recognizing cardiometabolic disorders. Am J Med. 2016 Jan;129(1):74-81.e2. PMID:26302146

12. The problem of overweight and obesity. Obesity: preventing and managing the global epidemic. Report of a WHO Consultation. Geneva: World Health Organization; 2000:5-37 (WHO Technical Report Series 894).

13. Janiszewski PM, Janssen I, Ross R. Does waist circumference predict diabetes and cardiovascular disease beyond commonly evaluated cardiometabolic risk factors? Diabetes Care. 2007;30(12):3105-9. PMID:17712026

14. Qiao Q, Nyandorj R. Is the association of type II diabetes with waist circumference or waist-to-hip ratio stronger than that with body mass index? Eur J Clin Nutr. 2010;46(1):30-4. PMID:19724291

15. Cheng CH, HO CC, Yang CF, Yang YC, Huang YC, Lai CH. Waist to hip ratio is a better anthropometric index than Body Mass Index for predicting the risk of Type 2 diabetes in Taiwanese population. Nutr Res. 2010;30(9):585-93.

16. Jia Z, Zhou Y, Liu X, Wang Y, Zaho X, Wang Y, et al. Comparison of different anthropometric measures as predictors of diabetes incidence in a Chinese population. Diabetes Res Clin Practice. 2011;92:265-71.

17. Hsieh SD, Yoshinaga H, Muto T. Waist-to-height ratio, a simple and practical index for assessing central fat distribution and metabolic risk in Japanese men and women. Int J Obesity. 2003;27:610-6.

18. Qihan ZHU, Feixia SHEN, Tingting YE, Qi ZHOU, Huihui DENG, Xuejiang GU. Waist-to-height ratio is an appropriate index for identifying cardiometabolic risk in Chinese individuals with normal body mass index and waist circumference. J Diabetes. 2014;6:527-34.

19. The Expert Committee on the diagnosis and classification of diabetes mellitus: Follow-up report on the diagnosis of diabetes mellitus. Diabetes Care, 2003;26(11):3160-7.

20. American Diabetes Association. Diagnosis and classification of diabetes mellitus. Diabetes Care. 2013;36(Suppl. 1)S67-S74.

21. IDF consensus worldwide definition of the metabolic syndrome. Brussels: International Diabetes Federation Belgium, 2006:1-23 (https://www.idf.org/e-library/consensus-statements/, accessed 3 January 2018).

22. Al-Riyami AA, Afifi N, Distribution and correlates of total impaired fasting glucose in Oman. East Mediterr Health J. 2003;9:37789.

23. Al-Shafaee MA, Ganguly SS, Bhargava K, Duttagupta KK. Prevalence of metabolic syndrome among prediabetic Omani adults: a preliminary study. Metab Syndr Relat Disord. 2008;6:275-9. PMID:19067531

24. Browning LM, Hsieh SD, Ashwell M. A systematic review of waist-to-height ratio as a screening tool for the prediction of cardiovascular disease and diabetes: 0.5 could be a suitable global boundary value. Nutr Res Rev. 2010;23:247-69. PMID:20819243

25. Walia R, Bhansali A, Ravikiran M, Ravikumar P, Bhadada SK, Shanmugasundar G, et al. High prevalence of cardiovascular risk factors in Asian Indians: a community survey - Chandigarh Urban Diabetes Study (CUDS). Indian J Med Res. 2014;139(2):252-9. PMID:24718400

26. Ayah R, Joshi MD, Wanjiru R, Njau EK, C Otieno F, Njeru EK, et al. A population-based survey of prevalence of diabetes and correlates in an urban slum community in Nairobi, Kenya. BMC Public Health. 2013;13:371. PMID:23601475 
27. Mausner JS, Kramer S, Mausner B. Epidemiology: an introductory text. Philadelphia: WB Saunders; 1985:221.

28. Hanley JA, McNeil BJ. A method of comparing the areas under receiver operating characteristic curves derived from the same cases. Radiology. 1983;148(3):839-43. PMID:6878708

29. Hosmer DW, Lemeshow S. Applied regression. New York: John Wiley \& Sons, 1989.

30. Ashwell M, Gunn P, Gibson S. Waist-to-height ratio is a better screening tool than waist circumference and BMI for adult cardiometabolic risk factors: systematic review and meta-analysis. Obes Rev. 2012;13:275-86. PMID:22106927

31. Al Safar HS, Jamieson SE, Cordell HJ, Blackwell JM, Tay GK. Heritability of quantitative traits associated with type 2 diabetes in an extended family from the United Arab Emirates. Int J Diabetes Metab. 2011;19:59-62.

32. Bhaktha G, Nayak S, D'Souza NDR, Shantaram M. Microalbuminuria (MAU) and its relationship with anthropometric variables in Type 2 diabetic and non diabetic females of Dakshina Kannada district in Indian population. Int J Pharmacy Biol Sci. 2011;1(3):341-6.

33. Jayawardana R, Ranasinghe P, Sheriff MHR, Matthews DR, Katulanda P. Waist to height ratio: A better anthropometric marker of diabetes and cardio-metabolic risks in South Asian adults. Diabetes Res Clin Pract. 2013;99(3):292-9.

34. Morison KM, Xu L, Tranopolosky M, Yusuf Z, Atkinson SA, Yusuf S. Screening for dysglycemia in overweight youth presenting for weight management. Diabetes Care. 2012;35(4):711-6. PMID:22271926

35. Khader YS, Batieha A, Jaddou H, Batieha Z, El-Khateeb M, Ajlouni K. Anthropometric cutoff values for detecting metabolic abnormalities in Jordanian adults. Diabetes Metab Syndr Obes. 2010;18(3):395-402. PMID:21437109

36. Gordis Leon. Epidemiology, 3rd ed. Philadelphia: Elsevier Saunders; 2004:79. 